\title{
Residual Stress Measurements of Front Window Welds in a Prototypical Spallation Neutron Source Target Module
}

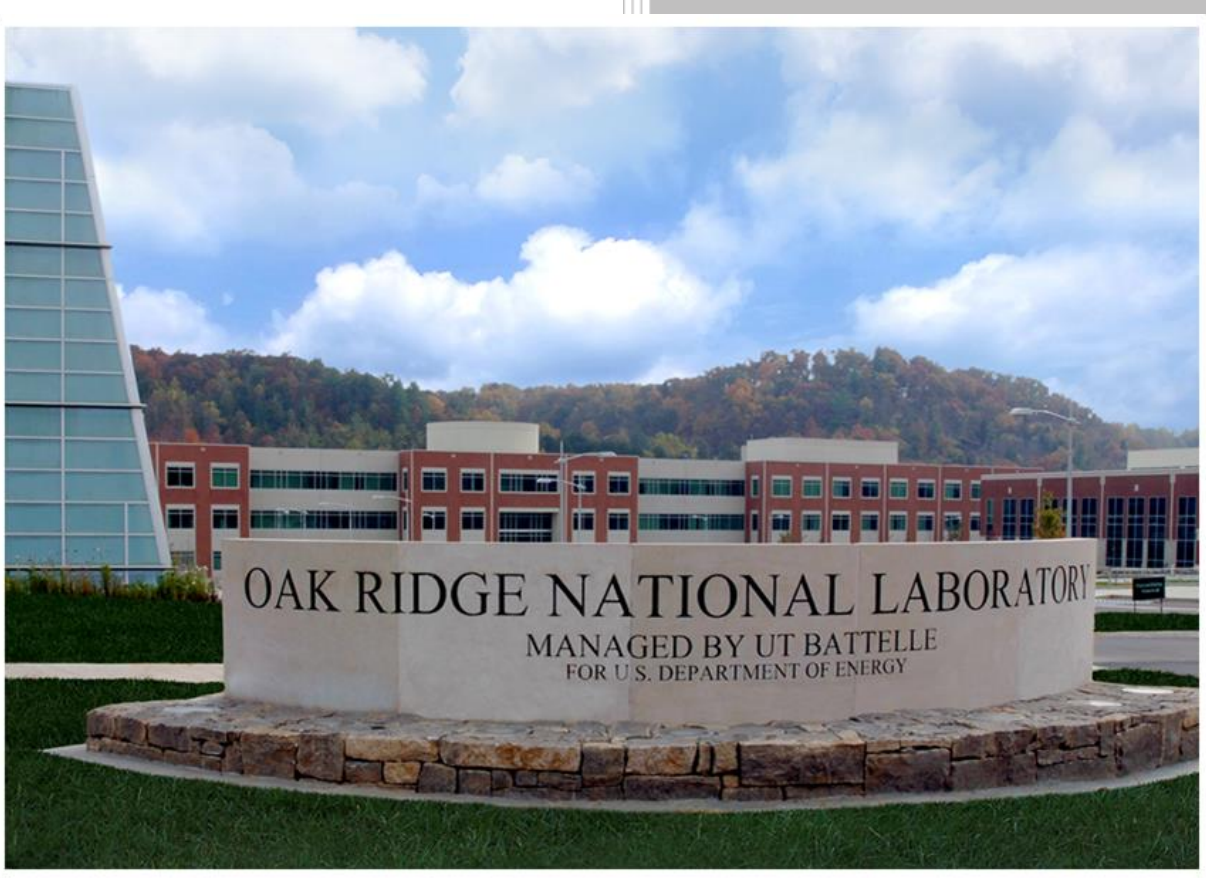

Ke An

David McClintock

Matthew Frost

February 2018

Approved for public release Distribution is unlimited. 


\title{
DOCUMENT AVAILABILITY
}

Reports produced after January 1, 1996, are generally available free via US Department of Energy (DOE) SciTech Connect.

Website http://www.osti.gov/scitech/

Reports produced before January 1, 1996, may be purchased by members of the public from the following source:

\author{
National Technical Information Service \\ 5285 Port Royal Road \\ Springfield, VA 22161 \\ Telephone 703-605-6000 (1-800-553-6847) \\ TDD 703-487-4639 \\ Fax 703-605-6900 \\ E-mail info@ntis.gov \\ Website http://classic.ntis.gov/
}

Reports are available to DOE employees, DOE contractors, Energy Technology Data Exchange representatives, and International Nuclear Information System representatives from the following source:

Office of Scientific and Technical Information

PO Box 62

Oak Ridge, TN 37831

Telephone 865-576-8401

Fax 865-576-5728

E-mail reports@osti.gov

Website http://www.osti.gov/contact.html

This report was prepared as an account of work sponsored by an agency of the United States Government. Neither the United States Government nor any agency thereof, nor any of their employees, makes any warranty, express or implied, or assumes any legal liability or responsibility for the accuracy, completeness, or usefulness of any information, apparatus, product, or process disclosed, or represents that its use would not infringe privately owned rights. Reference herein to any specific commercial product, process, or service by trade name, trademark, manufacturer, or otherwise, does not necessarily constitute or imply its endorsement, recommendation, or favoring by the United States Government or any agency thereof. The views and opinions of authors expressed herein do not necessarily state or reflect those of the United States Government or any agency thereof. 
Neutron Scattering Division

Neutron Technologies Division

Spallation Neutron Source

Oak Ridge National Laboratory

\title{
RESIDUAL STRESS MEASUREMENTS OF FRONT WINDOW WELDS IN A PROTOTYPICAL SPALLATION NEUTRON SOURCE TARGET MODULE
}

\author{
Ke An \\ David McClintock \\ Matthew Frost
}

Date Published: February 2018

\author{
Prepared by \\ OAK RIDGE NATIONAL LABORATORY \\ Oak Ridge, TN 37831-6283 \\ managed by \\ UT-BATTELLE, LLC \\ for the \\ US DEPARTMENT OF ENERGY \\ under contract DE-AC05-00OR22725
}





\section{CONTENTS}

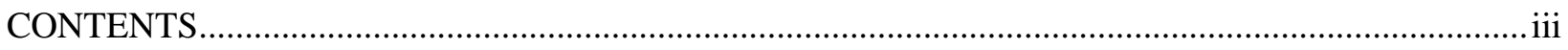

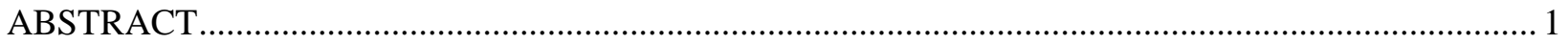

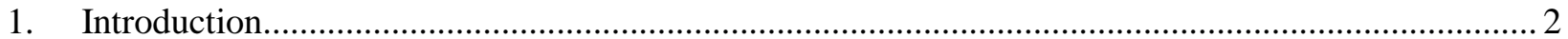

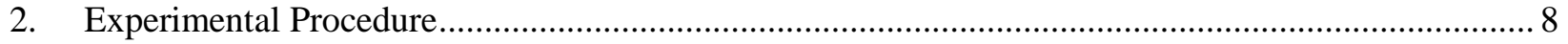

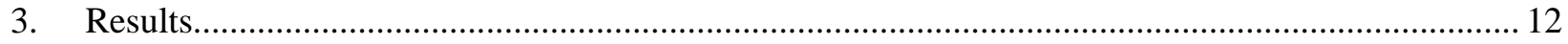

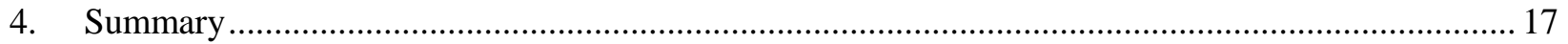

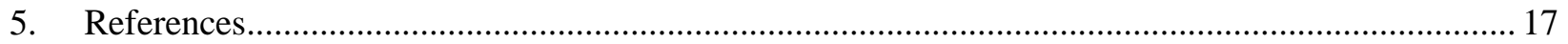




\begin{abstract}
Spallation Neutron Source (SNS) target modules are fabricated from 316L stainless steel by welding together sections of machined components using electron beam welding. The failure of the tenth operational SNS target (Target 10) at an electron beam weld prompted an investigation into the residual stress remaining in the weld joint after joining to determine if welding procedures for SNS target fabrication produce detrimental residual stresses in or near the welds. Due to an issue with fabrication, the front section of an SNS target was removed from fabrication and made available for residual stress measurements. The residual stresses in an electron beam weld joining the front window and front body of the target prototype was measured at several locations near EBW2 weld between outer window and front body using the VUCLAN instrument. Different stress free $d_{0}^{h k l}$ methods were used to calculate the residual strain and residual stress. The results show tensile residual stress up to $350 \mathrm{MPa}$ along the weld direction which peaked at weld location.
\end{abstract}




\section{Introduction}

Neutrons at the Spallation Neutron Source (SNS) are produced by bombarding liquid mercury flowing through a target module with high energy $(\sim 1 \mathrm{GeV})$ proton pulses at a frequency of $60 \mathrm{~Hz}$. While liquid mercury is the actual spallation target material, a target module is utilized to contain and transport the flowing mercury. The target module is fabricated from 316L stainless steel and is designed to introduce mercury to the target region of the SNS monolith and return the heated mercury to the process loop for heat removal. The target module is actually two vessel structures, as shown in Figure 1: an inner mercury vessel and a water-cooled vessel, called the water-cooled shroud. The mercury target material flows through the inner mercury vessel, while the water-cooled shroud encases the mercury vessel and is designed to contain mercury in the event of a leak.

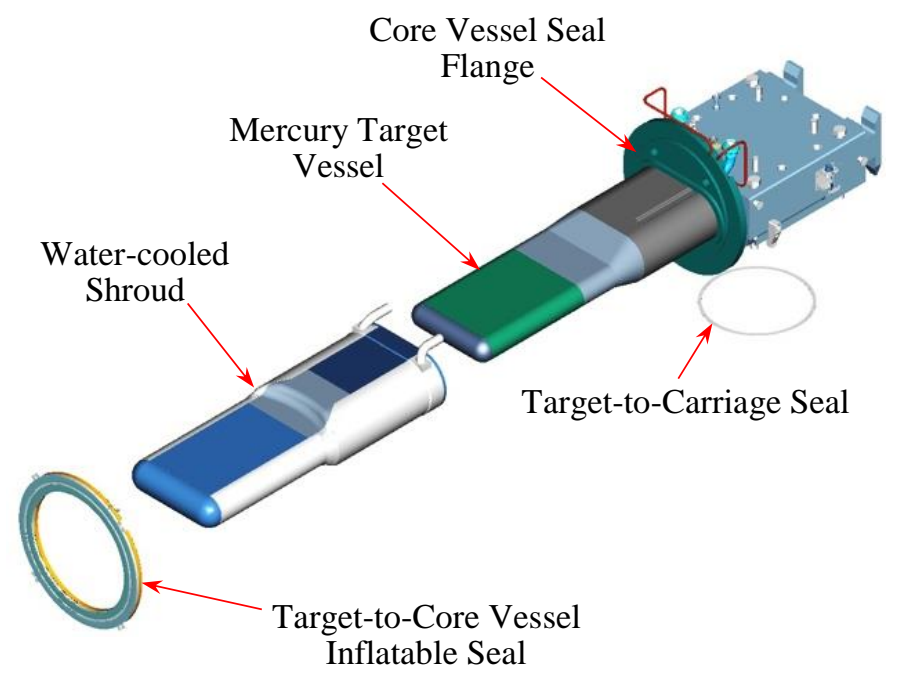

Figure 1. Schematic of SNS target module showing the mercury target vessel and water-cooled shroud.

The mercury vessel is fabricated by welding several large machined components together, as shown in Figure 2 (a). Most welds are electron beam welds (EBW), due to the strict dimensional requirements of the SNS target module; the minimal heat input from EBW greatly reduces the amount of thermally-induced distortion imparted to the target vessel when compared to traditional fusion methods such as tungsten inert gas (TIG) welding. Recent studies have also shown that welding via EBW does not appreciably degrade the carbon atmosphere in the hardened Kolsterising ${ }^{\circledR}$ layer near welds in SNS target vessels [1].

EBW requires highly accurate electron beam positioning and weld control parameters that must be established during pre-fabrication weld development efforts. Welding with an electron beam also produces discontinuities and artifacts that require manual repair "over" welds using TIG welding. These spot-repair welds are used to repair areas with porosity and weld underfill. But TIG repair welds introduce an appreciable amount of heat to the weld region and potentially increase the residual stress at or near the weld. 


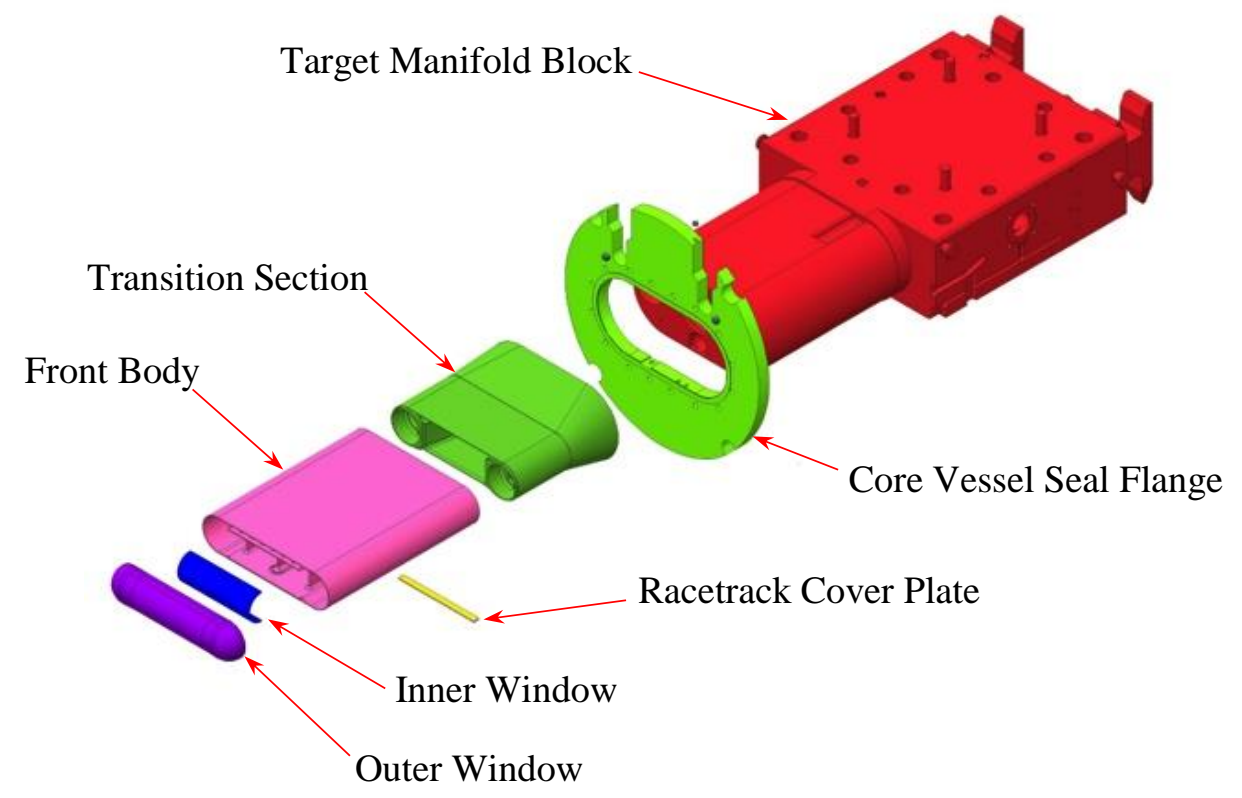

(a)

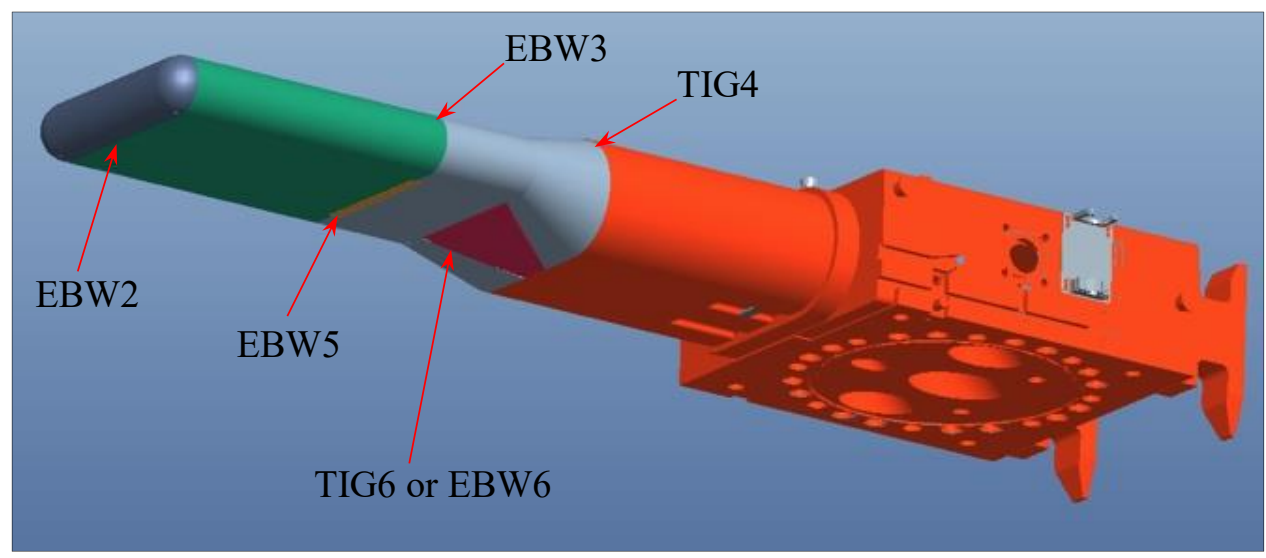

(b)

Figure 2. (a) Schematic of SNS target major components and (b) diagram of electron beam welds (EBW) and tungsten inert gas (TIG) welds used to fabricate the SNS mercury target vessel.

The tenth operational target (Target 10) at the SNS developed a leak during service, which was located at the circumferential ("racetrack") weld joining the target front body and transition section, called EBW3, shown in Figure 2 (a). The cause of the leak was unknown when the leak was located, but the leak location, shown in Figure 3 (a), suggested it was associated with the EBW3 weld joint. A decision was made to sample the leak location and investigate the factors contributing to the vessel failure.

A sampling device was designed to remove the section of Target 10 containing the leak location by cutting a "core sample" from the EBW3 weld using a 4in $(10.2 \mathrm{~cm})$ diameter annular cutter, as shown in Figure 3 (b). A sample containing the leak location was removed from Target 10 and examined under a subcontract with Westinghouse (Pittsburg, PA) to determine the cause(s) of the leak. The weld contained in the leak location sample was methodically sectioned and characterized to understand the factors that led 
to failure of Target 10 and develop engineering design changes to address the vulnerabilities identified during the examinations.

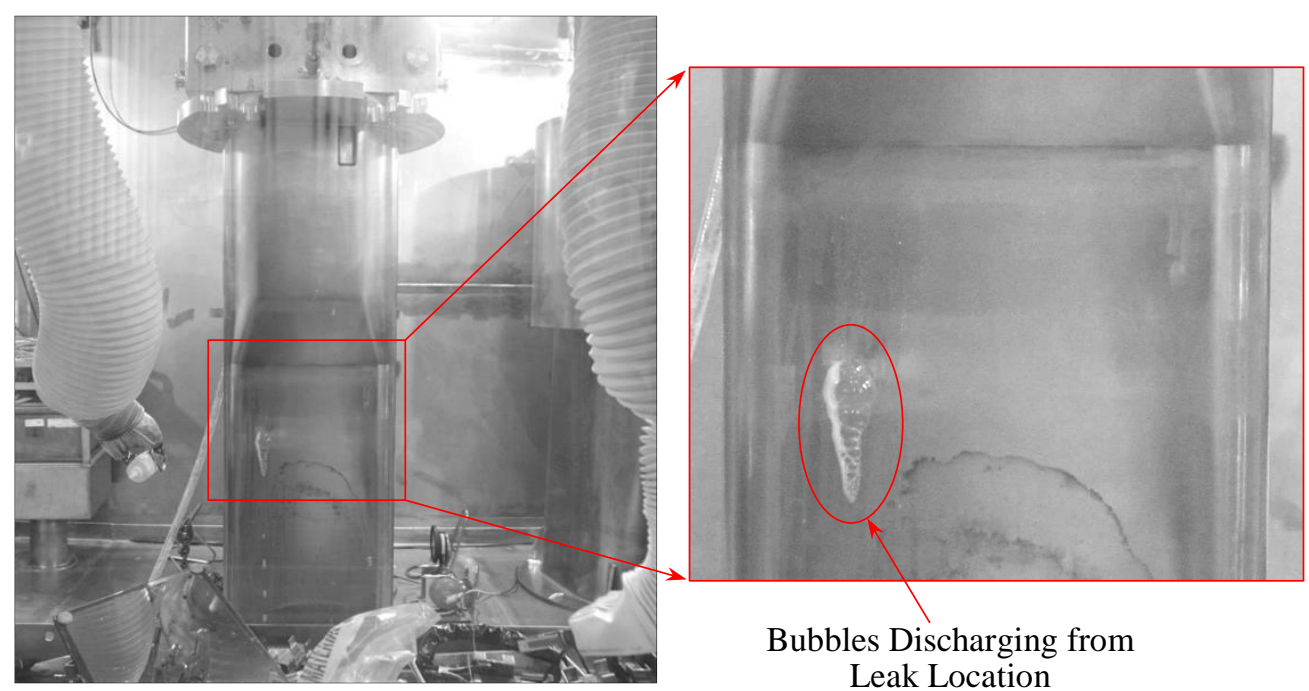

(a)

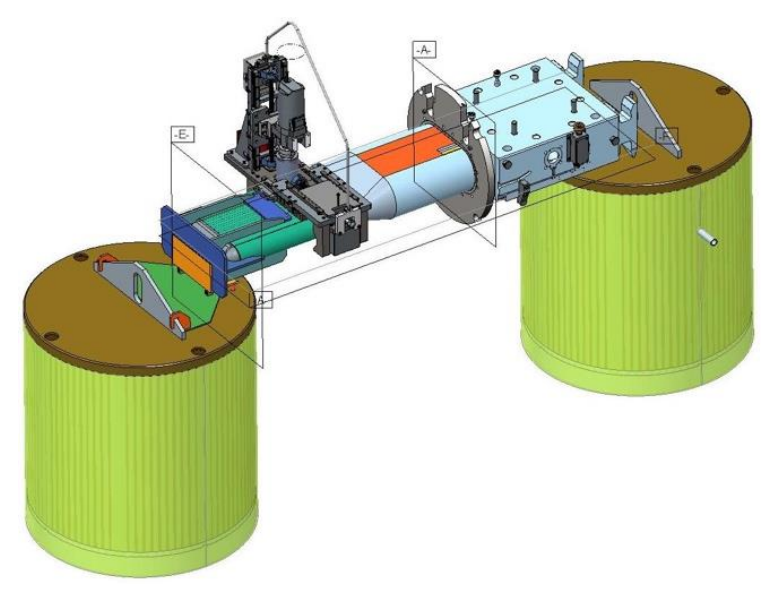

(b)

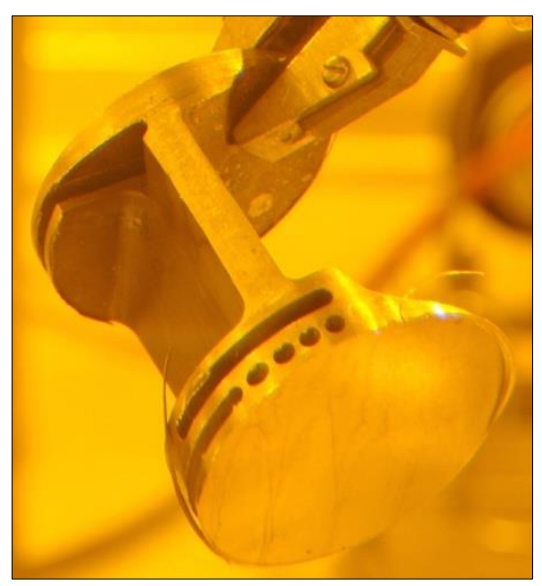

(c)

Figure 3. (a) Images of bubbles emerging from the Target 10 leak location, (b) schematic of the Target 10 sampling operating, and (c) picture of the Target 10 sample containing the leak location.

Metallography of the EBW 3 weld in Target 10 showed that the weld had insufficient penetration depth at the leak location, and multiple weld overpasses were performed on the joint. The majority of the EBW3 weld is a full-penetration weld, where the electron beam melted and fused material along the entire depth of the weld faying surfaces. The section of the EBW3 weld in Target 10 where the leak was located was a partial-penetration weld, where an area of the faying surfaces at the weld root were not melted and fused together, as shown in the diagram of the EBW3 faying surfaces in Figure 4. Areas with partial-penetration welds were part of the original SNS target design and subsequent design changes have eliminated all areas where partial-penetration welds originally specified. 


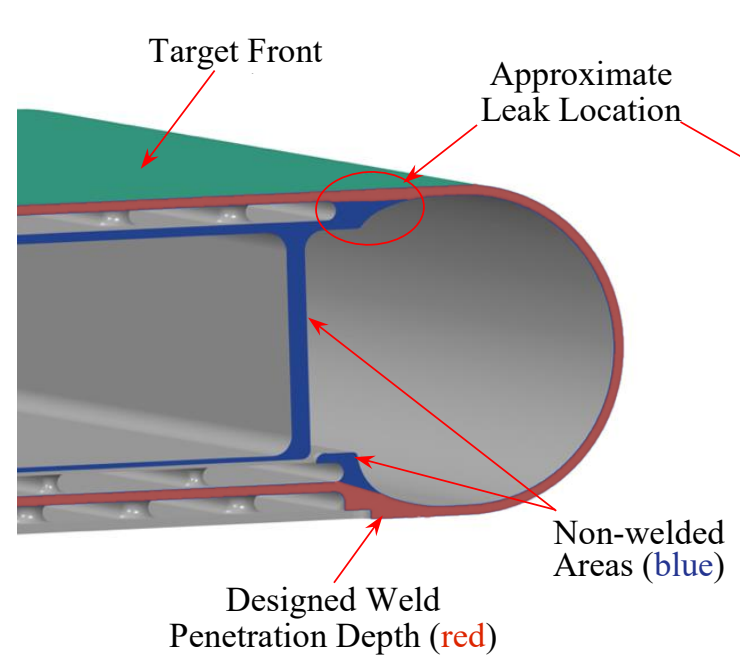

(a)

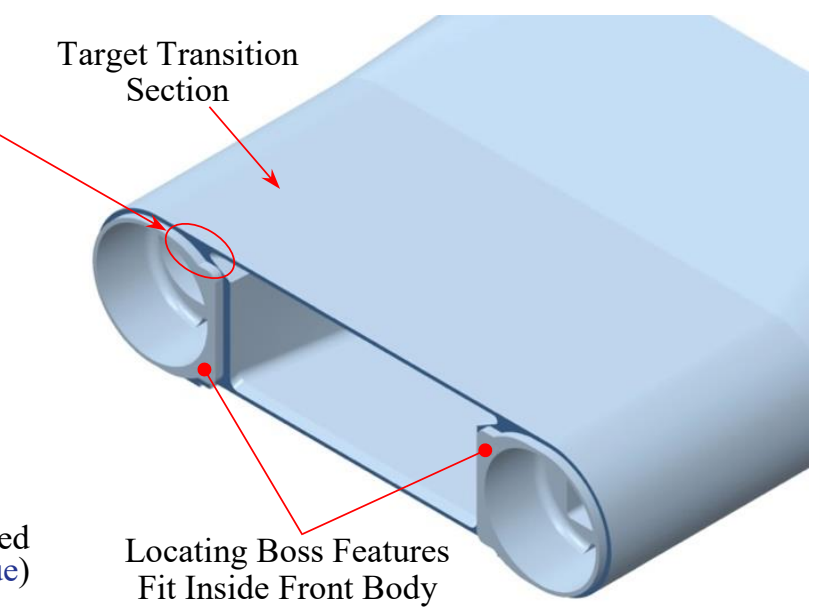

(b)

Figure 4. Schematic of the EBW3 faying surfaces for the SNS target (a) the front body and (b) transition section.

During the examination of the Target 10 leak location sample fatigue striations were observed on the fracture surface at the leak, and the cause of the leak was attributed to fatigue crack growth from the stress concentration formed at the root of the partial-penetration weld. During the examinations of the EBW3 weld several overpasses were observed over the original EBW, as shown in Figure 5. The primary EBW is the long narrow region that penetrates through the faying surfaces into the weld backer, while the weld overpasses are shallow broad regions near the surface of the target vessel. Also, shown in Figure 5 is a shift in the faying surface that occurred during welding; evidence of the shift in the faying surfaces can be seen near the bottom of the primary EBW in Figure 5. The shift is evidence that the region of the target near the faying surfaces was stressed during welding and movement occurred to remove these stresses.

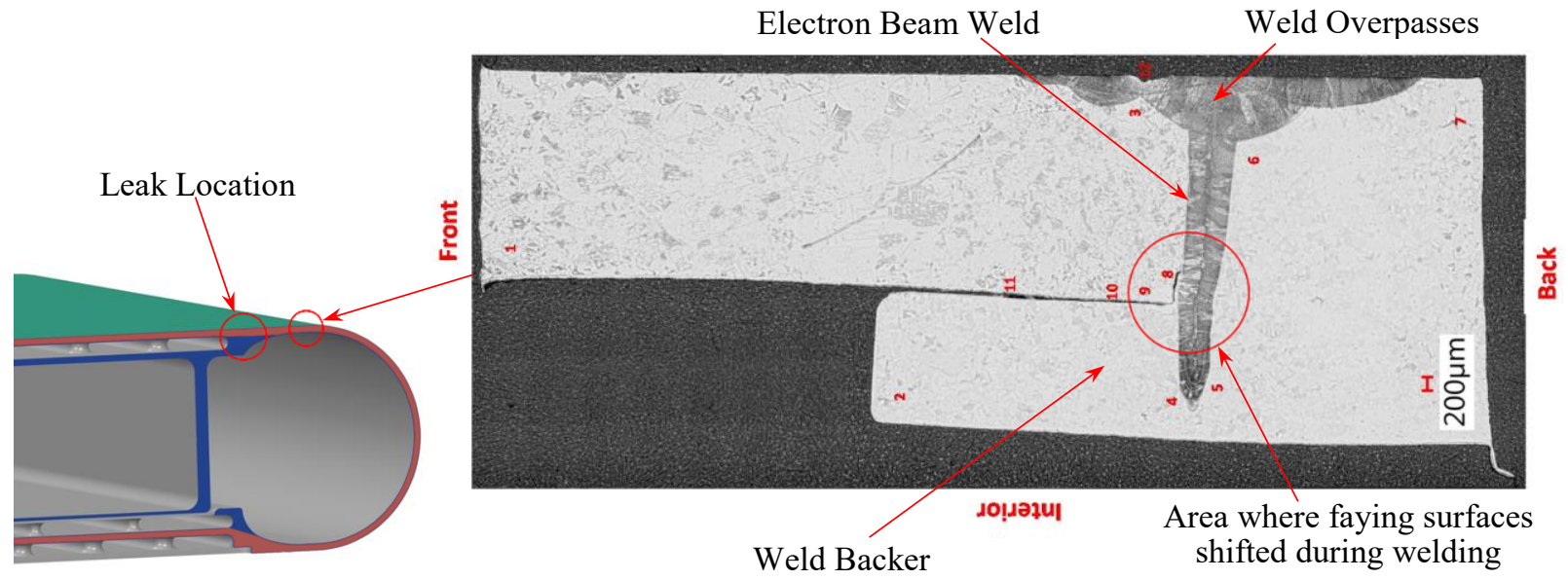

Figure 5. Image from metallography of EBW 3 showing cross section of weld near the Target 10 leak location.

Another discovery made during the examination of the EBW3 weld in Target 10 was cracking on the vessel interior surface that were oriented perpendicular to the weld line. During examination of samples 
from the Target 10 EBW3 weld, cracks were observed emanating perpendicular from the weld line, as shown in Figure 6. The cracks were observed on most sections of the Target 10 EBW3 weld and metallography specimens containing the cracks were produced to further examine the near-weld cracking.

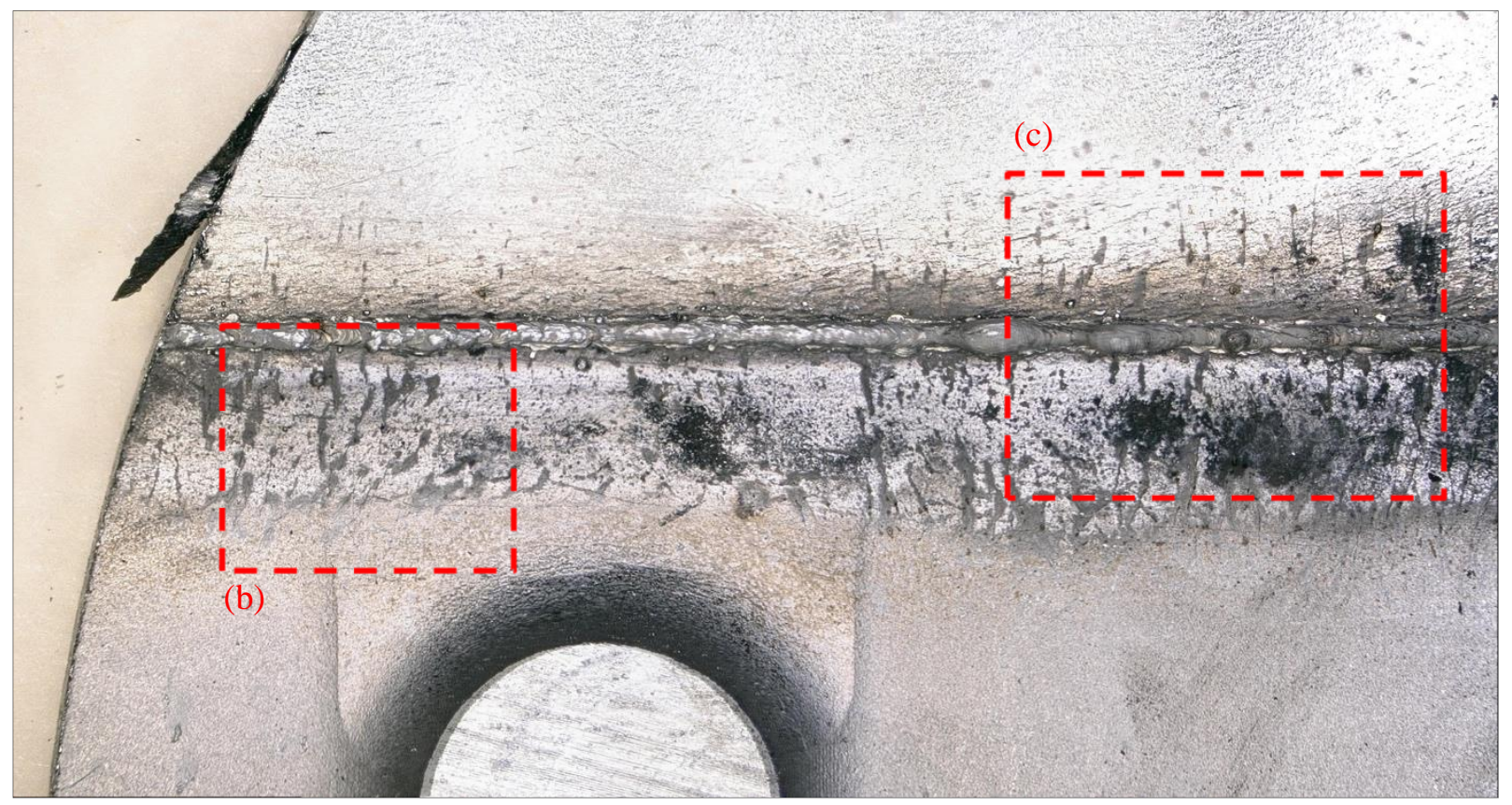

(a)

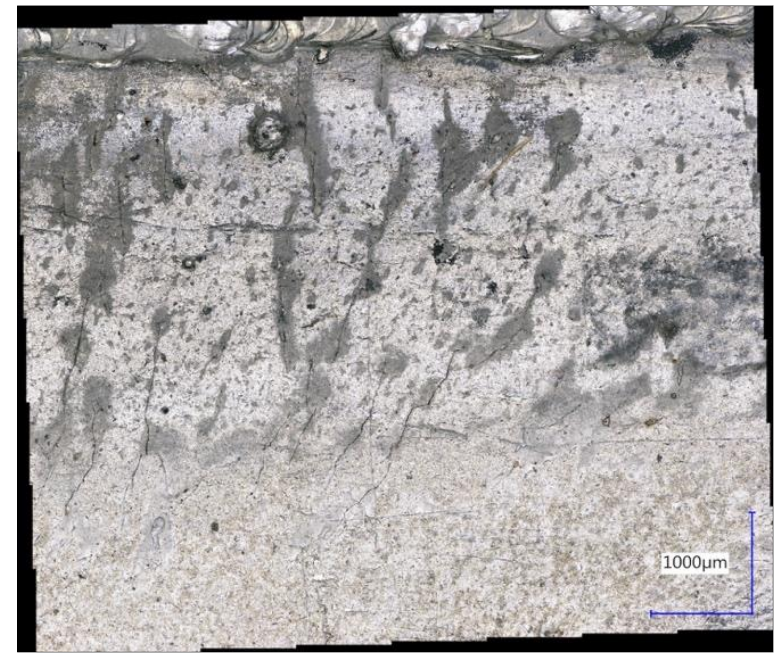

(b)

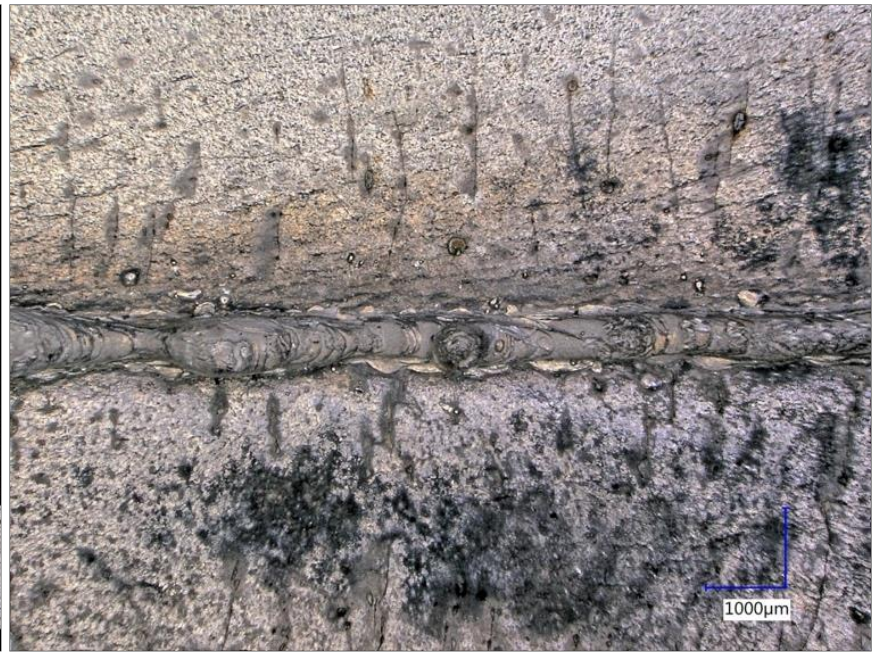

(c)

Figure 6. (a) Image of EBW3 weld from Target 10 sample, (b) and (c) highlighted areas of cracks on the vessel surface emanating from EBW3.

Metallography specimens containing the "perpendicular" cracks were prepared such that the crosssection of the crack depth into the vessel material were viewed. Optical micrographs, shown in Figure 7, of the cracks showed that they are relatively shallow cracks, and only extended approximately $50 \mu \mathrm{m}$ into the vessel material. The depth of the cracks corresponded with the depth of the hardened Kolsterising ${ }^{\circledR}$ layer 
that is applied to the SNS mercury target vessel [2]. While the cracks appear to be associated with the depth of the Kolsterising ${ }^{\circledR}$ layer, currently the cause of the perpendicular cracking is not known.
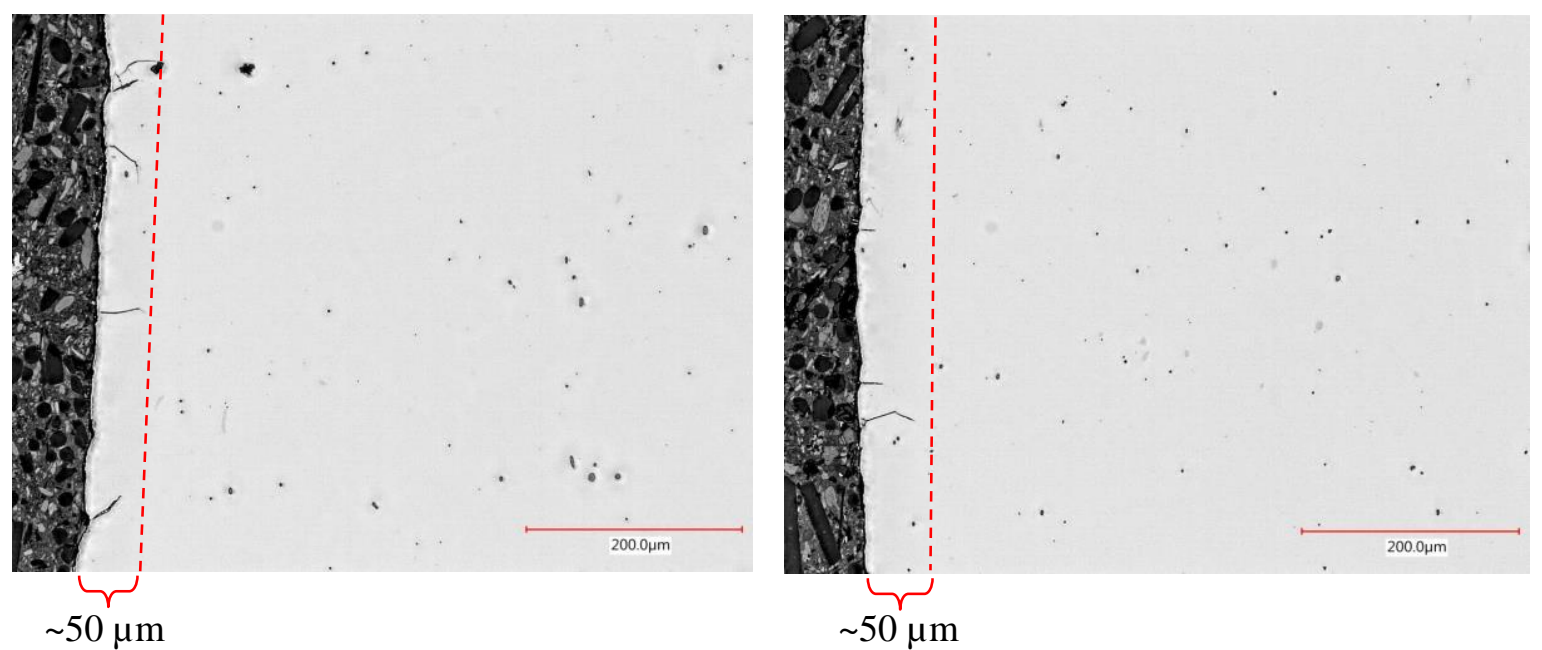

Figure 7. Micrographs of cross-section samples through the perpendicularly oriented cracks emanating from the EBW3 weld with markers indicating a depth of $50 \mu \mathrm{m}$.

The observations of shifting during welding, numerous weld overpasses, and perpendicular cracking near welds prompted discussions regarding the stress state at and near the welds used to fabricate SNS target vessels. Concerns that the weld designs used to fabricate SNS targets might be causing the artifacts that were observed in the Target 10 EBW3 prompted an effort to measure the residual stresses at/near welds in SNS targets. During fabrication of SNS target serial number MTX-008 an error in the design drawings was identified that resulted in a slightly thinner mercury vessel wall at the sides of the outer window. A decision was made to cut off the MTX-008 front body assembly with the thinner window and fabricate a replacement with the full inner wall thickness.

The front body of the MTX-008 section that was removed contained the two electron beam welds that join the inner and outer windows to the front body designated EBW1 and EBW2, respectively. The weld configuration for these two welds were similar to the EBW3 weld, which provided an opportunity to examine prototypic electron beam welds that are similar to the failed weld in Target 10 . The weld designs for the inner and outer windows allow examination of any systemic issues with the electron beam welding techniques used to fabricate SNS targets and to determine if residual stresses remaining at/near the welds present a vulnerability to the target design. 


\section{EXPERIMENTAL PROCEDURE}

\subsection{Instrument Settings}

The residual stress measurement was conducted on the VULCAN instrument [3]. A schematic view of the instrument setup is show in Figure 8. Neutron diffraction measures the diffraction peaks of the ( hkl) lattice planes whose normals are parallel to Q1 and Q2 direction, respectively. Strain components along these two directions are measured sinutannelsy from Bank 1 and Bank 2. The gauge volume was determined by the incident slits and receiving collimators. A $2 \times 2 \times 2 \mathrm{~mm}^{3}$ gauge is set for all the measurements. At the SNS, the diffraction patterns of multipeaks of alloys can be measured once with wide wavelenght spectrum determined by the double disk choppers. The choppers were set running at $30 \mathrm{~Hz}$ with the center wavelength at $2.0 \AA$, which allows a measurable $d$ spacing from 0.5 to $2.4 \AA$. While the intensity of different hkls show change of preferred grain orientation, the calculation of the residual strain is based on the FCC (311) peak which shows least intergranullar strain of the stainless steel, or in another word, its lattice strain behaves linearly with applied stress.

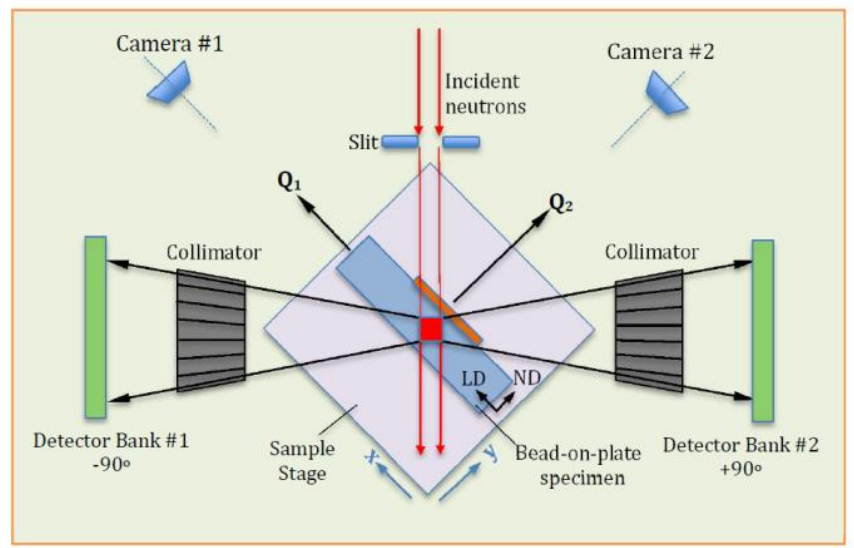

Schematic illustration of the bead-on-plate experimental set-up on VULCAN (top view, not to scale). The $-90^{\circ}$ and $+90^{\circ}$ detector banks record diffraction peaks of the (h $\mathrm{k} \mathrm{l}$ ) lattice planes whose normals are parallel to $\mathrm{Q}_{1}$ and $\mathrm{Q}_{2}$, respectively. Strain components along these two directions are measured simultaneously. The bead-on-plate specimen is positioned on top of the sample stage and aligned at $45^{\circ}$ from the incident beam.

Figure 8. VULCAN instrument configuration for residual lattice strain measurement.

\subsection{Measurement Set-up}

A line in the shell near the incident beam side and perpendicular to the weld was chosen for the residual strain measurement. It is $108 \mathrm{~mm}$ from the side edge of the target body as shown in Figure 9. $1 \mathrm{~mm}$ step is chosen for the spatially resolved residual strain measurement. The locations are middle points of the thickness of the measured locations. 


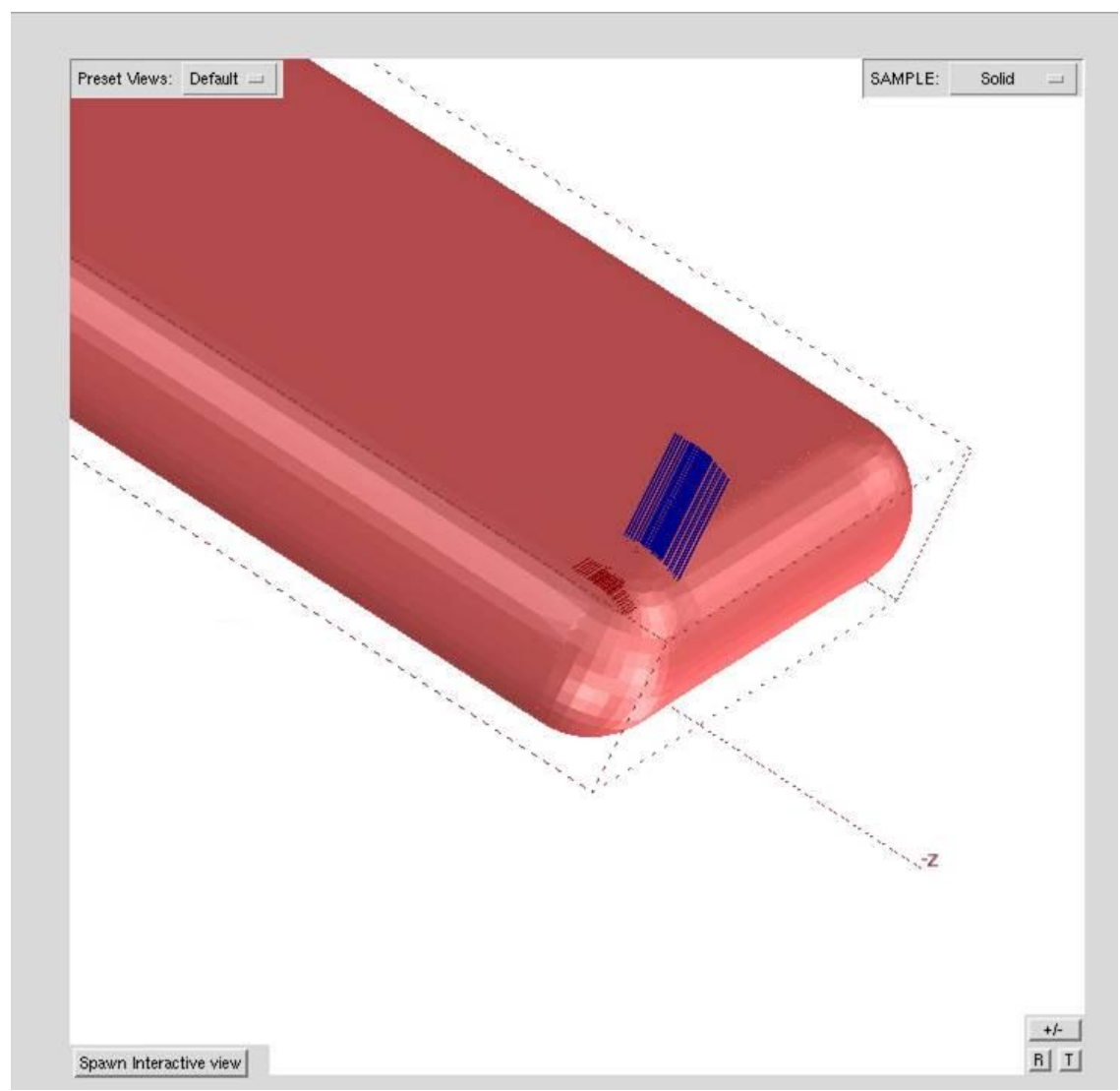

Figure 9. Measurement locations as shown in the SScanSS software. The blue and brown lines show the measurement vectors at each locations.

The target front body was mounted on the sample stage with two orientations to measure the lattice in three orghorgonal directions which are required for stress calculation. Figure 10 and Figure 11 show the sample mounts which allow to measure the longitudinal, transverse, and normal directions with respect to the weld (EBW2). 


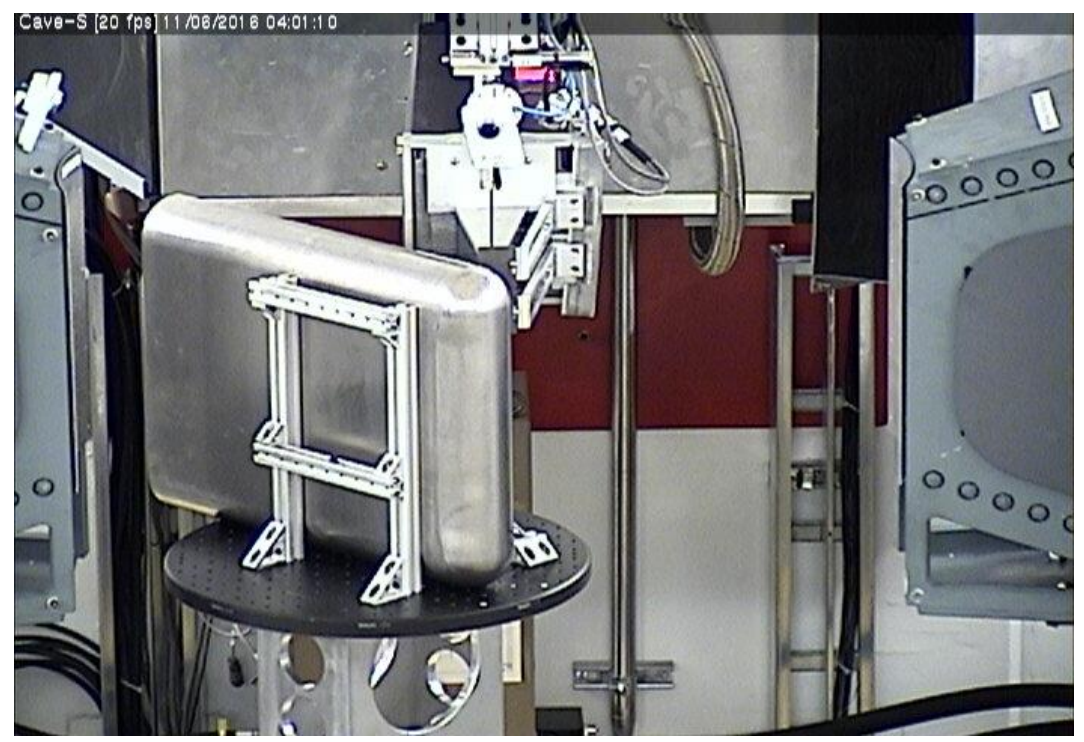

(a)

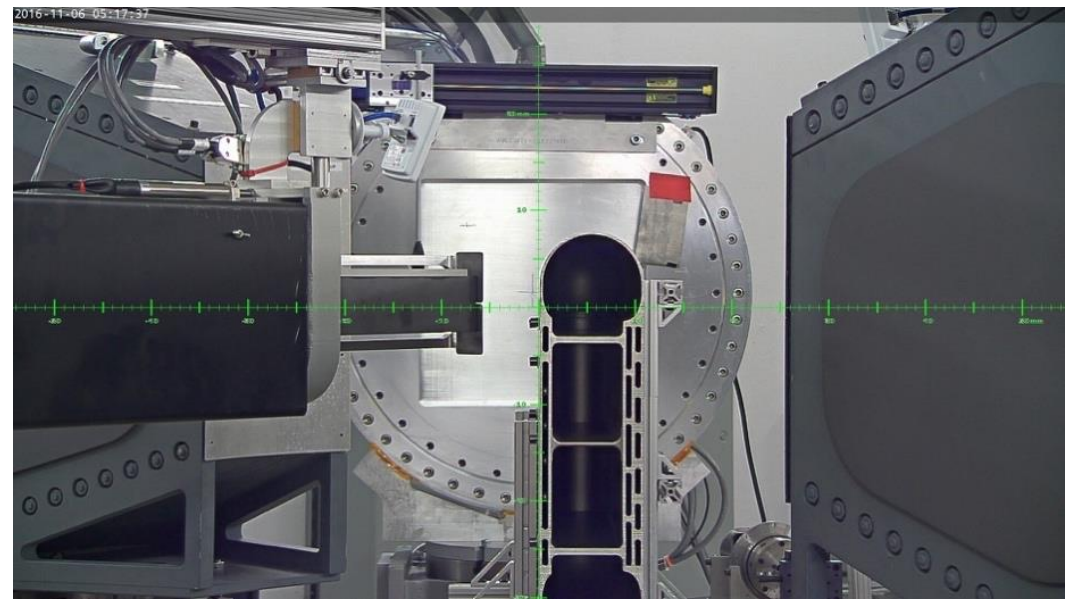

(b)

Figure 10. (a) Configuration to measure lattice change in transverse direction (TD/B1) and normal direction (ND/B2). (b) a view along the transverse direction ( scale is off due to the magnification of the camera). 


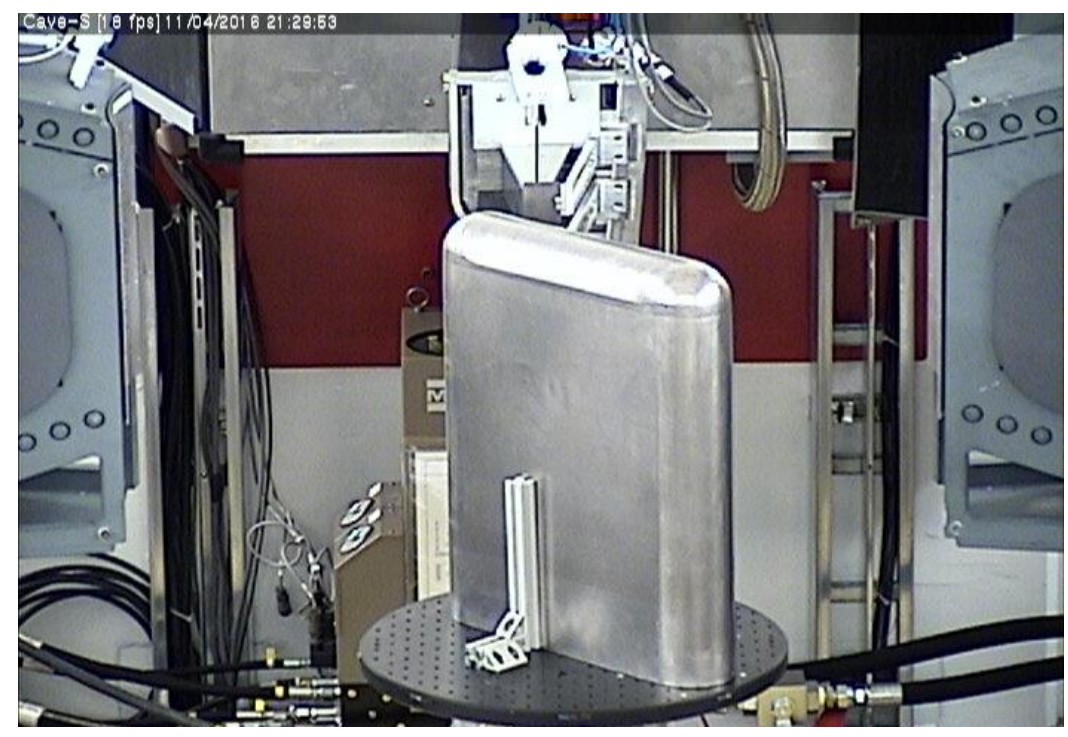

Figure 11. Configuraiton to measure lattice change in longitudinal direction (LD/B1) and a repeat of normal direction (ND/B2).

\subsection{Determination of Stress by Neutron Diffraction}

To obtain the residual stress by meausring the lattice spacing $d$, an analogy of Hooke's law can be used. Given the measurment of orthorgonal lattice strains, the orthogonal components of stress tensor $\left(\sigma_{i i}\right)$ can be calculated from the strain components $\left(\varepsilon_{i i}\right)$ :

$$
\sigma_{i i}=\frac{E^{h k l}}{\left(1+v^{h k l}\right)}\left\{\varepsilon_{i i}^{h k l}+\frac{v^{h k l}}{1-2 v^{h k l}}\left(\varepsilon_{11}^{h k l}+\varepsilon_{22}^{h k l}+\varepsilon_{33}^{h k l}\right)\right\}
$$

where $i=1,2,3$ is the index for three orthogonal directions, transverse direction (TD), longitudinal direction (LD), and normal direction (ND), respectively. $E^{311}=185 \mathrm{GPa}$ and $v^{311}=0.33$ are the diffraction elastic constants for reflection $\left(\begin{array}{lll}3 & 1 & 1\end{array}\right)$. The $(h k l)$-specific lattice strain $\varepsilon_{i i}^{h k l}$ can be determined as:

$$
\varepsilon_{i i}^{h k l}=\frac{d_{i i}^{h k l}}{d_{0}^{h k l}}-1
$$

Usually, a stress free condition is reqired so the stress free lattice $d$ spacing can be determined. In a welding sample, typically, combing a similar coupon which is usually a direct cut piece from samples is used to release stresses. This was not available for this target sample provided when the neutron residual stress measurments were conducted. We proposed a few methods to determine the $d_{0}^{h k l}$. One is using the far locations from the EBW weld by assuming no welding process induced residual stress. This will not be able to exclude manufacturing induced residual stresses. The other method is using calculated $d_{0}^{h k l}$ at measurment locations by assuming through thickness stress is close to zero, i.e. a plane stress condition. To show this, the fomulars below are adopted from previously published work for thin additively manufactured samples [4]. 
By assigning $A=\frac{E^{h k l}}{1+v^{h k l}}, B=\frac{v^{h k l}}{1-2 v^{h k l}}$, and replacing the strain components in Eq. (1) with that expressed in Eq. (2), the stress can be written as:

$$
\sigma_{i i}=A\left\{\frac{d_{i i}^{h k l}}{d_{0}^{h k l}}-1+B\left(\frac{d_{11}^{h k l}}{d_{0}^{h k l}}-1+\frac{d_{22}^{h k l}}{d_{0}^{h k l}}-1+\frac{d_{33}^{h k l}}{d_{0}^{h k l}}-1\right)\right\}
$$

In a plane stress condiciton, when ND stress $\sigma_{33}=0, d_{0}^{h k l}$ can be determined from the measured peak positions $d$ :

$$
\begin{aligned}
& \sigma_{33}=A\left\{\frac{d_{33}^{h k l}}{d_{0}^{h k l}}-1+B\left(\frac{d_{11}^{h k l}}{d_{0}^{h k l}}-1+\frac{d_{22}^{h k l}}{d_{0}^{h k l}}-1+\frac{d_{33}^{h k l}}{d_{0}^{h k l}}-1\right)\right\}=0 \\
& d_{0}^{h k l}=\frac{d_{33}^{h k l}+B\left(d_{11}^{h k l}+d_{22}^{h k l}+d_{33}^{h k l}\right)}{1+3 B}
\end{aligned}
$$

thus, $d_{0}^{h k l}$ can be determined at every location regarless of the compositional inhomogeneity and its effects on $d_{0}^{h k l}$. By replacing $d_{0}^{h k l}$ in Eq. (3), the stress components $\sigma_{11}$ and $\sigma_{22}$, along the LD and TD directions, can be solved when $d_{11}, d_{22}$ and $d_{33}$ are measured.

\section{RESULTS}

Examples of detector intensity distributions and the diffraction patterns when the mockup target sat in horizontal direction are shown in Figure 12. In Figure 12 (a), the detector intensities plot reflects inhomgeousity of grain sizes in the materials, where the front body material shows large scattered spots due to grains with large size, and this can be visually seen in the microstructure SEM in Figure 5. The large grains make neutron diffraction residual stress measurement unique because of its large gauge volume which contains large number of grains for determining the macroscopic lattice strain. Diffractions in Figure 12 (b) and (c) show the materials also possess different manufacturing textures where the relative reflection intensities are not same as a result of different preferred grain orientation in the materials. However the texture is not strong and its effect on diffraction elastic constants is not considered in the residual stress calcuation. Bank 1 data showed less scattering intensity due to longer neutron path lengths in compared to the Bank 2 data. The counting criterion was set for (311) peak in Bank 1 when the measured peak intensity was above 300 counts to ensure acceptable fitting error. Single peak fitting of (311) peak was conducted by using the VDRIVE software [5], and an example of peak fitting is shown in Figure 13. 

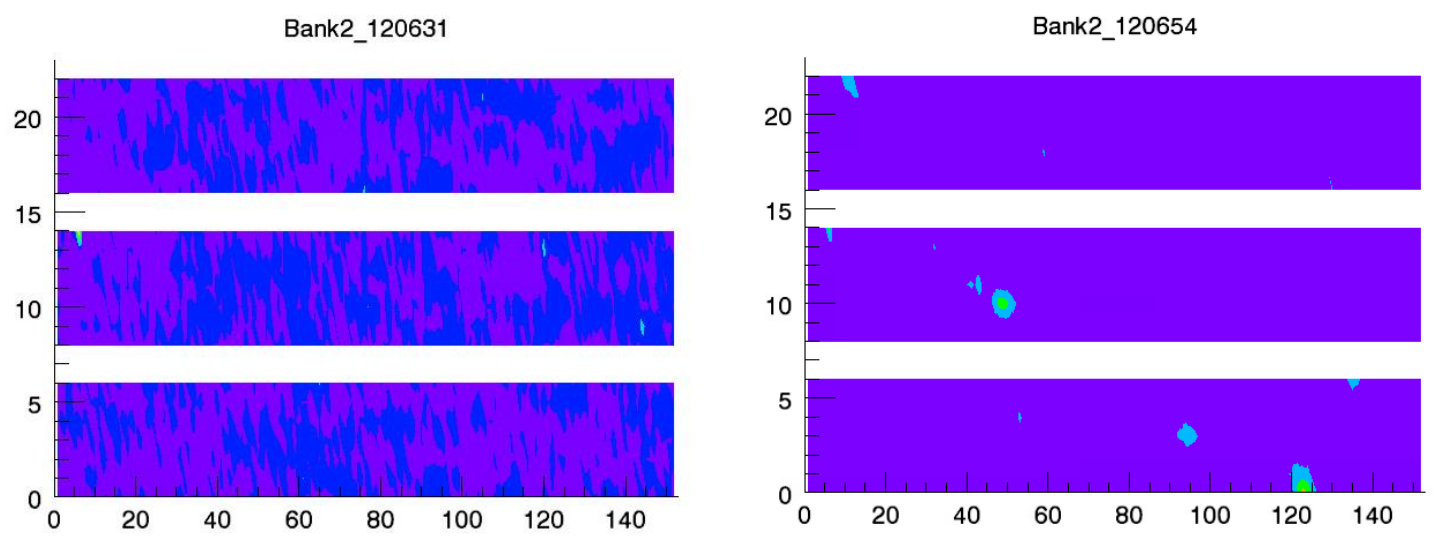

(a) Detector intensity distributions of measured locations in outer window (left) and front body (right).

Run120654 Bank 1

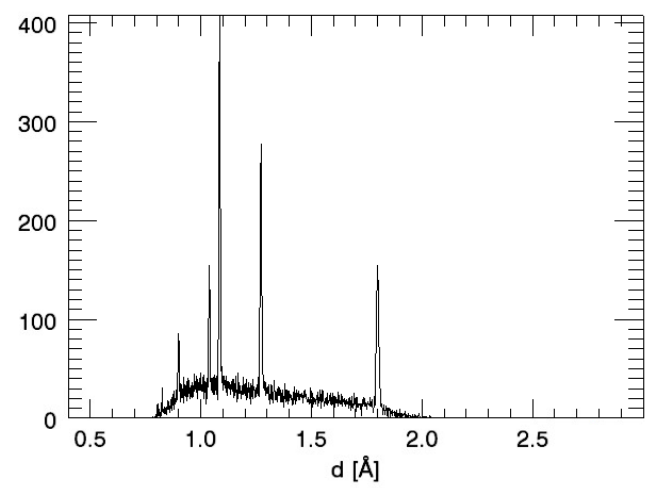

Run120654 Bank 2

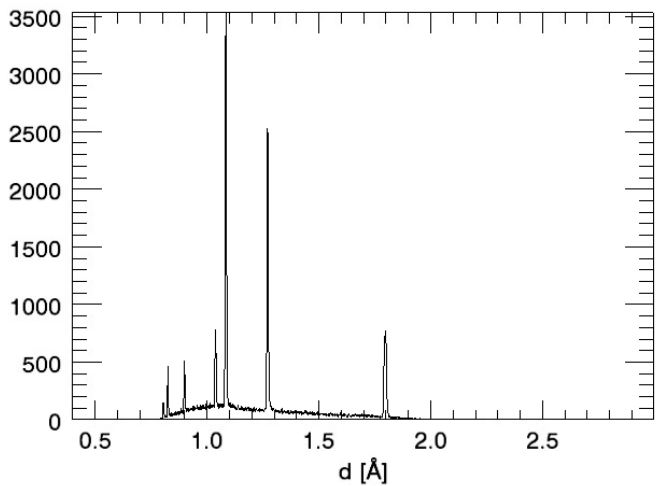

(b) Example diffractions from front body side near EBW2 while sample was positioned horizontally.

Run120638 Bank 1

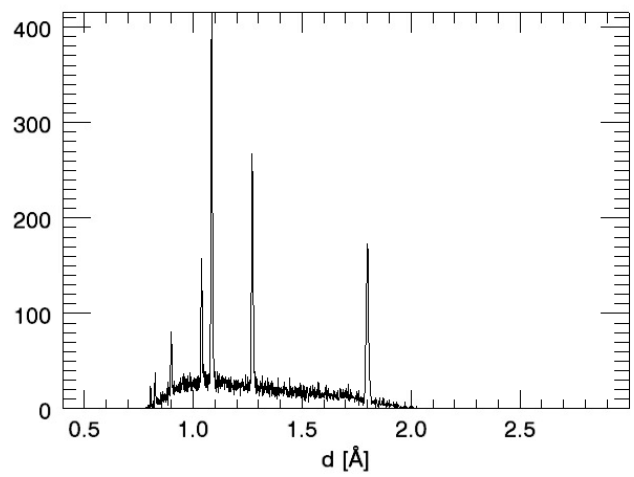

Run120638 Bank 2

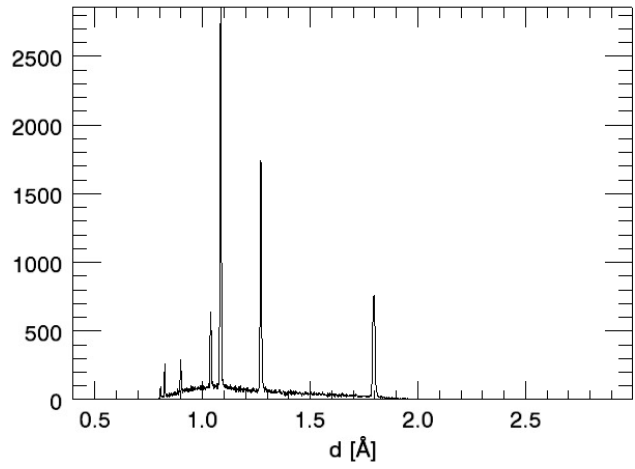

(c) Example diffractions from EBW2 while sample was positioned horizontally. 

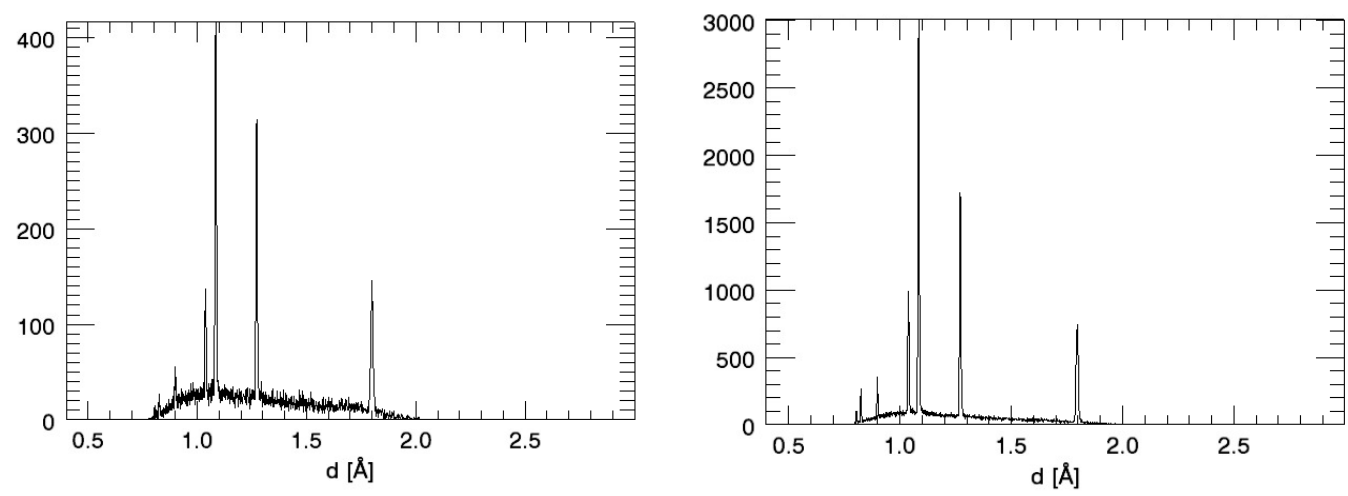

(d) Example diffractions from outer window side near EBW2 while sample was positioned horizontally.

Figure 12. (a) detector (Bank 2) intensity distributions in the outler window and front boday locations, and example diffraction patterns from locations, in the front body (b), in the EBW2 (c), and in the outer window (d). Bank 1 measured TD and Bank 2 measured ND lattices in each locations. The intensity differences come from different neutron path lengths where measuruing TD and LD took longer ones than ND.

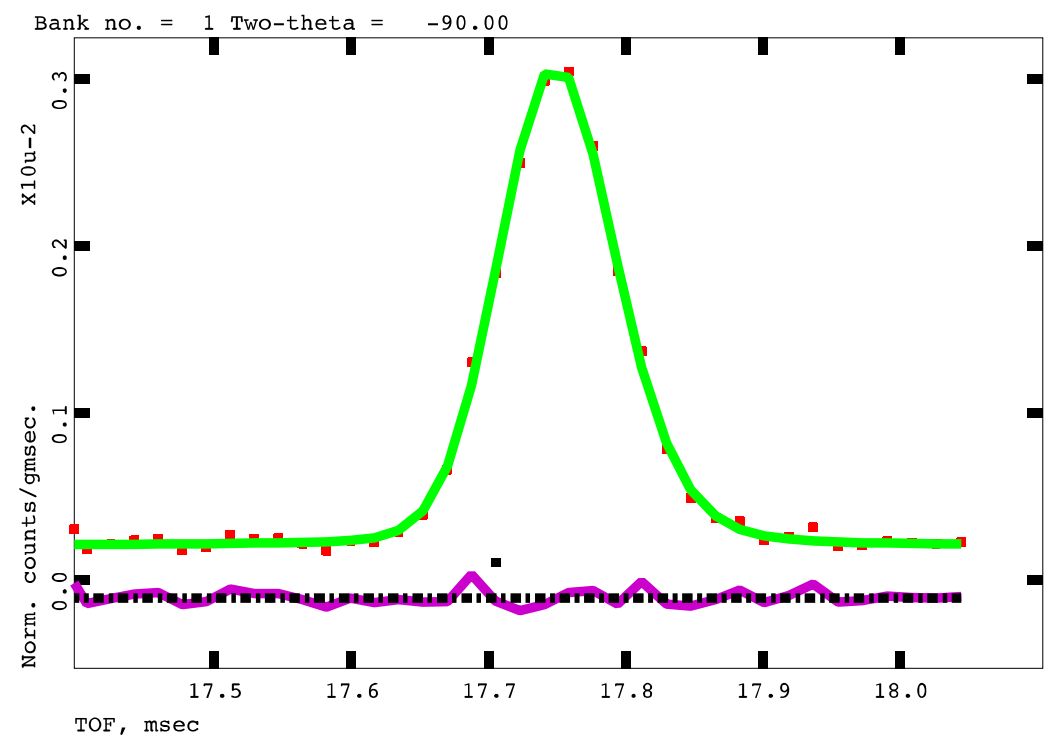

Figure 13. Single peak fitting of a (311) peak by VDRIVE [5].

The lattice strains and calculated residual stresses in the three orthogonal directions by using different $d_{0}^{h k l}$ strategies are shown in Figure 14. Figure 14 (a) shows the result by taking the last positon in the outer window which is about $11 \mathrm{~mm}$ from the planned reference weld line. Longitudinal strain is most profound as expected, where the weld region shows strong tension. The other directions show less absolute amplitudes. The calculated stresses in three directions show similar trend with maxima in the weld. 
However, the strains in the front body far from the weld do fluctuate where the welding effect should be minimum. This indicates the improper choice of the $d_{0}^{h k l}$ for the measured locations. Similarly, when taking furthest locations in the front body, the overall trend did not change as expected but the absolute maximum strain value in LD increased as much as $500 \mu \varepsilon$. This proves again the differences in the chosen $d_{0}^{h k l}$ in the two materials. This is not a surprise, as shown in the previous diffraction results, that although the materials are labeled as 316L, there are significant differences in the microstructure and after welding the chemistry will differ due to the thermal processes that occur during melting and solidification. Thus, the calculated $d_{0}^{h k l}$ method will allow a good estimate of residual stress in the structure regardless of the chemistry or microstructure, given the plane stress conditions. Figure 14 (c) shows the calculated residual strains and residual stresses by taking ND stress as zero. The peak LD stress is about $350 \mathrm{MPa}$, and relaxed to a stress of $150 \mathrm{MPa}$ approximately 7-10 mm away from the peak in both sides. Transverse stress is relatively small even across the weld as there is no physical structural constrain for building up stress. It has to be noted here that the stress calculated based on the plane stress assumption reflects the overall stress in the measured locations including manufacturing and welding.

The tensile LD residual stress is typical in welding due to the thermal history of welding process, i.e. during the cooling process, thermal residual stress develops between the weld and the base metal or heat effected zones. However, there should be a compressive stress in LD directions to balance the high tensile stress. In this measurement, the stress is always in tension in the measured locations as shown in Figure 14 (c). On the other hand, there seems to be near or below 0 residual LD stress as in Figure 14 (a) and Figure 14 (b) in the front body. The main difference of the three methods is the choice of $d_{0}^{h k l}$. In Figure 14 (c), the stress is based on the assumption of the plane stress condition, which may differ from the real condition, and as mentioned before the calculated stress also includes manufacturing stresses. Also, the structure is large and the balance may not be limited on the measured line. For future work, to solve this, a combed stress relieved sample for exact locations should be provided for this thermally induced residual stress measurement, and more beam time is recommended for measuring a 2-D stress/strain distribution. 

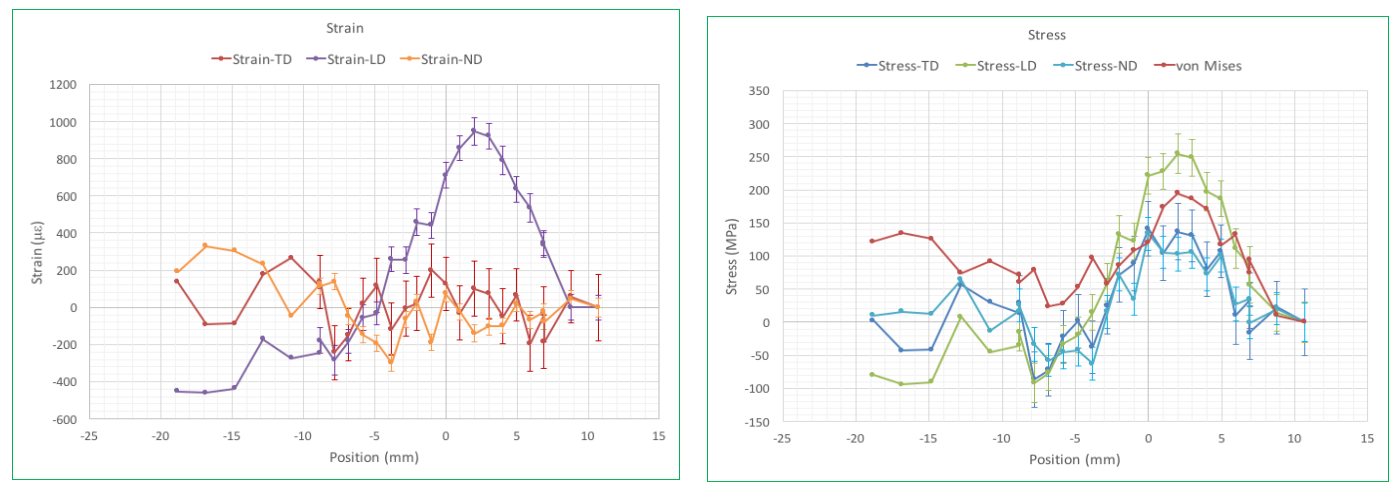

(a) Residual strains and calculated residual stress by taking furthest location measured in outer window.
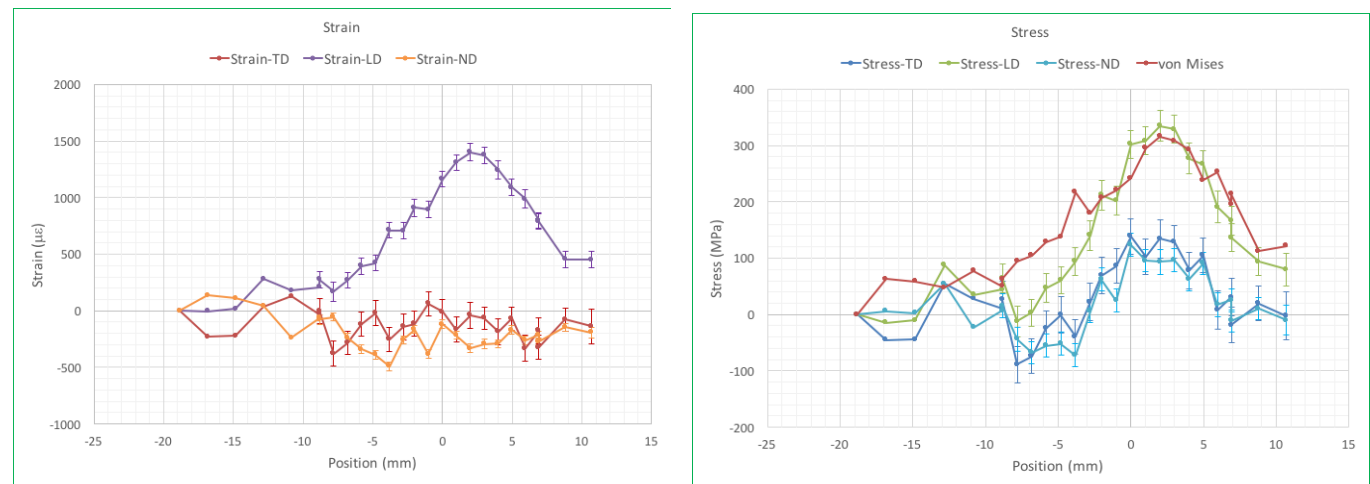

(b) Residual strains and calculated residual stress by taking furthest location measured in front body.
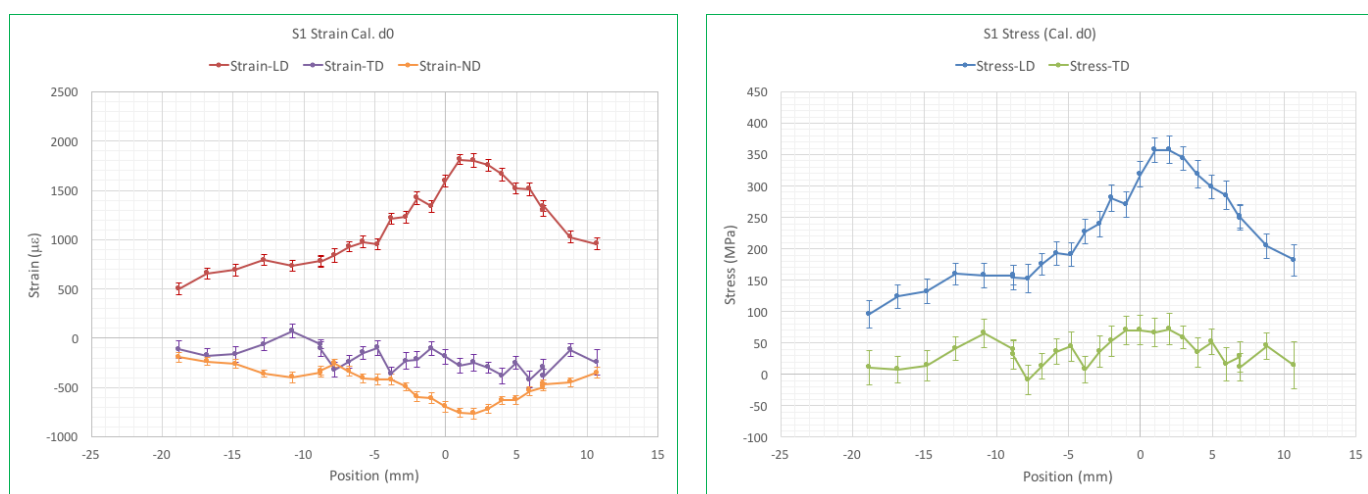

(c) Residual strains and calculated residual stress by taking plane stress assumption in the structure.

Figure 14. Residual strains and stresses across EBW2 by using different d0 methods. 


\section{SUMMARY}

The residual stresses in an electron beam weld joining the front window and front body of the target prototype was measured at several locations near EBW2 weld between outer window and front body using the VUCLAN instrument. Different stress free $d_{0}^{h k l}$ methods were used to calculate the residual strain and residual stress. The results show tensile residual stress up to 350MPa along the weld direction which peaked

at weld location. A combed stress relieved sample shall be taken for $d_{0}^{h k l}$ determination and characterizing the thermally induced residual stress due to welding.

\section{REFERENCES}

[1] David McClintock, Maxim Gussev, Donovan Leonard, Drew Winder, "Characterization of Weld Designs Used to Fabricate Spallation Neutron Source Target Modules”, SNS Technical Report 106010101-TR0018-R00.

[2] David A. McClintock, James W. Hyres, Bradley J. Vevera, Journal of Nuclear Materials 450 (2014) 176-182.

[3] K. An, H.D. Skorpenske, A.D. Stoica, Dong Ma, X.L. Wang, and E. Cakmak, "First in-situ lattice strains measurements under load at VULCAN", Metallurgical and Materials Transactions A, 2011, Volume 42, Number 1, Pages 95-99.

[4] K. An, L. Yuan, L. Dial, I. Spinelli, A. D. Stoica, Y. Gao, Non-destructive Residual Stress Measurement and Finite Element Simulation in a Curved Thin-Walled Structure by Laser Powder Bed Fusion Additive Manufacturing, Materials and Design, Volume, 135, 122-132, 2017.

[5] K. An, VDRIVE, a VULCAN Data Reduction and Interactive Data Visualization Software for Event Mode Neutron Diffraction, ORNL TM-2012-621, 2012. 